\title{
ESTABELECIMENTO IN VITRO DE PORTA-ENXERTOS DE Prunus sp. ${ }^{1}$
}

\author{
MARCELO COUTO ${ }^{2}$, RAFAEL UCKER BRAHM ${ }^{3}$, ROBERTO PEDROSO DE OLIVEIRA ${ }^{4}$
}

\begin{abstract}
RESUMO - O objetivo deste trabalho foi avaliar o estabelecimento in vitro de cinco cultivares de porta-enxerto de Prunus sp. em variações de dois meios de cultura. O material vegetal foi obtido de plantas-matrizes cultivadas em telado, sendo a desinfestação realizada em soluções à base de álcool e hipoclorito de sódio. Utilizou-se um esquema fatorial 5 x 2 (cultivares Aldrighi, Barrier, Capdeboscq, Flordaguard e GF677 x formulações salinas $1 / 2 \mathrm{MS}$ e QL), distribuído em blocos casualizados, compostos por quatro repetições, com cinco tubos de ensaio cada uma, sendo inoculado um segmento nodal por tubo. $\mathrm{O}$ cultivo dos explantes foi realizado por quatro semanas, em ambiente com $20 \mu \mathrm{Em}^{-2} \mathrm{~s}^{-1}, 24 \pm 4^{\circ} \mathrm{C}$ e fotoperíodo de 16 horas. Independentemente do meio de cultivo, os porta-enxertos 'Barrier', 'Capdebosq' e 'Flordaguard' apresentaram maiores porcentagem de explantes estabelecidos e número de brotações, sendo os mais responsivos in vitro. A formulação salina $1 \frac{1}{2} \mathrm{MS}$ foi a mais indicada para o estabelecimento da cultivar GF677, enquanto a QL para a 'Aldrighi'. Não foram observadas plântulas com sintomas de clorose, vitrificação ou encarquilhamento, indicando que as condições de cultura utilizadas foram satisfatórias. As maiores porcentagens de contaminação foram verificadas nas cultivares Aldrighi (72\%) e Capdeboscq (41\%), as quais são as mais utilizadas na região Sul do Brasil.
\end{abstract}

Termos para indexação: cultura de tecidos, pessegueiro, porta-enxerto.

\section{IN VITRO ESTABLISHMENT OF Prunus sp. ROOTSTOCKS}

ABSTRACT - The aim of this work was to establish five Prunus sp. rootstocks on two media cultures. The explants were obtained from mother plants cultivated in greenhouse. Desinfestation was carried out in alcohol and sodium hypochlorid solutions. The experiment was a factorial with five cultivars ('Aldrighi', 'Barrier', 'Capdeboscq', 'Flordaguard' and 'GF677') and two culture media (1/2MS and QL). The experimental design was of completely randomized blocks, with four replications with five test tubes per plot. A nodal segment was introduced per test tub. The explant culture was maintained at $24 \pm 4^{\circ} \mathrm{C}, 20 \mu \mathrm{E} \mathrm{m}^{-2} \mathrm{~s}^{-1}$ and 16 hours photoperiod for four weeks. Independently of culture medium, the rootstocks 'Barrier', 'Capdeboscq' and 'Flordaguard' showed higher in vitro response rate and higher number of shoots. 1/2MS medium was indicated to 'GF677' establishment and QL medium to 'Aldrighi'. In vitro abnormal plantlets were not observed, suggesting satisfactory conditions to culture. The higher contamination rate was verified in 'Aldrighi' (72\%) and 'Capdeboscq' (41\%), that are the rootstocks most used in southern Brazil.

Index terms: tissue culture, peach, rootstock.

A falta de mudas de alta qualidade genética, fitossanitária e fitotécnica é um dos principais fatores limitantes da cultura do pessegueiro no Brasil. Apesar disso, anualmente, são produzidas 150 mil toneladas de pêssego em uma área de 22 mil ha, sendo o Estado do Rio Grande do Sul responsável por 60\% da produção (Agrianual, 2003). Esta destina-se ao mercado de frutas frescas e à industrialização, sendo freqüente a realização de importações para atender à demanda interna (Chalfun \& Hoffmann, 1997).

A propagação do pessegueiro vem sendo realizada por meio de enxertia, utilizando porta-enxertos obtidos a partir de sementes, o que acarreta grande variabilidade genética do pomar (Fachinello et al., 1994). As principais cultivares utilizadas no Sul do Brasil são a 'Capdeboscq' e a 'Aldrighi’ (Mauch, 1991). Recentemente, pesquisadores da Embrapa Clima Temperado e da Universidade Federal de Pelotas vêm dedicandose à introdução e avaliação de novos porta-enxertos para Prunus sp.. Dentre as cultivares introduzidas, destacam-se a Barrier, Flordaguard e GF 677, que apresentam boa compatibilidade com praticamente todas as cultivares-copa de pessegueiro, nectarineira e amendoeira (Fachinello, 2000).

A cultivar Barrier, híbrido entre Prunus davidiana e P. persica, apresenta sistema radicular denso e profundo, adaptando-se a diferentes tipos de solo e condições de umidade; tolerância à asfixia de raiz e à clorose induzida por deficiência de ferro; e resistência moderada à maioria dos nematóides causadores de galhas (Felipe, 1994). A 'GF677', híbrido entre $P$. persica e $P$. amygdalus, vem sendo amplamente empregada na Europa por apresentar vigor pronunciado, tolerância a solos alcalinos e a seca, adaptação a solos pesados e possibilidade de replantio sem problemas de alelopatia (Berardi, 1996). A 'Flordaguard' é um híbrido entre $P$. persica x $P$. davidiana, apresentando vigor médio, baixa resistência à asfixia de raízes e resistência a nematóides (Fachinello, 2000).

A produção in vitro de porta-enxertos de pessegueiro vem sendo realizada de forma comercial em vários países, principalmente na
Itália (Loreti \& Massai, 1995), não sendo utilizada no Brasil em função da inexistência de um método economicamente viável. A micropropagação possibilita a produção massal de mudas livres de patógenos e com uniformidade genética, em pequeno espaço físico e curto período de tempo, de forma a atender às exigências das entidades certificadoras $\mathrm{e}$ às necessidades dos produtores por mudas de qualidade (Oliveira et al., 2001).

As principais limitações da micropropagação de Prunus referemse à oxidação dos explantes introduzidos in vitro, contaminação por bactérias, dificuldade de enraizamento e, principalmente, baixas taxas de estabelecimento e multiplicação dos explantes, havendo a necessidade de maiores estudos sobre o assunto (Couto, 2003).

Este trabalho teve por objetivo avaliar o estabelecimento in vitro de cinco porta-enxertos de Prunus sp., em variações de dois meios de cultura, visando a aumentar a eficiência da produção de mudas via micropropagação.

Brotações dos porta-enxertos 'Aldrighi', 'Barrier', 'Capdeboscq', 'Flordaguard' e 'GF677' foram coletadas de plantasmatrizes com dois anos de idade, cultivadas em telado. A coleta foi realizada em novembro de 2003, quando as plantas se encontravam na fase inicial de brotação. O terço apical das brotações, com comprimento de aproximadamente $10 \mathrm{~cm}$, foi cortado com auxílio de uma tesoura desinfestada com álcool a $70 \%$ e acondicionado em frasco contendo água destilada. A desinfestação foi feita imergindo as brotações em álcool a $70 \%$, por 1 minuto, e hipoclorito de sódio a $2 \%$, por 15 minutos. Em câmara de fluxo laminar, o material foi lavado três vezes com água destilada e esterilizada, procedendo-se, em seguida, o isolamento de segmentos nodais com 10-20 mm de comprimento.

Os segmentos nodais foram introduzidos in vitro, individualmente, em tubos de ensaio $(20 \times 150 \mathrm{~mm})$, contendo $10 \mathrm{~mL}$ das seguintes variações dos meios de cultura: a) Metade da concentração dos macronutrientes e concentração completa dos micronutrientes do MS (Murashige \& Skoog, 1962) (1/2MS); b) Macronutrientes do QL

\footnotetext{
(Trabalho 056/2004). Recebido:12/05/2004. Aceito para publicação: 19/10/2004.

${ }^{2}$ Eng. Agrôn., M.Sc., Doutorando em Agronomia, FAEM/UFPel. Caixa Postal 354. CEP 96010-900. Pelotas-RS. E-mail: couto@ cpact.embrapa.br. Bolsista Capes. ${ }^{3}$ Graduando de Ecologia, Universidade Católica de Pelotas. CEP 96010-000. Pelotas-RS. E-mail: rafaelubrahm@ bol.com.br. Bolsista FAPERGS.

${ }^{4}$ Eng. Agrôn., Dr., Pesquisador da Embrapa Clima Temperado. Caixa Postal 403. CEP 96001-970. Pelotas-RS. E-mail: rpedroso@cpact.embrapa.br. Bolsista CNPq.
} 
(Quoirin e Lepoivre, 1977) combinado com os micronutrientes do MS (QL). Ambos os meios foram suplementados com $0,7 \mathrm{mg} \mathrm{L}^{-1}$ de BAP (6benzilaminopurina), $10 \mathrm{mg} \mathrm{L}^{-1}$ de ácido ascórbico, $0,5 \mathrm{mg} \mathrm{L}^{-1}$ de ácido cítrico, $1 \mathrm{mg} \mathrm{L}^{-1}$ de ácido nicotínico, $2 \mathrm{mg} \mathrm{L}^{-1}$ de glicina, $0,5 \mathrm{mg} \mathrm{L}^{-1} \mathrm{de}$ piridoxina, $0,5 \mathrm{mg} \mathrm{L}^{-1}$ de tiamina, $100 \mathrm{mg} \mathrm{L}^{-1}$ de mioinositol, $30 \mathrm{~g} \mathrm{~L}^{-1} \mathrm{de}$ sacarose e $6 \mathrm{~g} \mathrm{~L}^{-1}$ de ágar, com $\mathrm{pH}$ ajustado para 5,8 antes da autoclavagem a $121^{\circ} \mathrm{C}$, por 15 minutos.

O estabelecimento in vitro dos explantes foi avaliado por meio de experimento fatorial, 2 (formulações salinas) x 5 (cultivares de portaenxerto), com delineamento em blocos casualizados, compostos por quatro repetições, contendo cinco tubos de ensaio cada uma.

$\mathrm{O}$ cultivo dos explantes foi realizado em ambiente com intensidade luminosa de $20 \mu \mathrm{Em}^{-2} \mathrm{~s}^{-1}$, fotoperíodo de 16 horas e temperatura de $24 \pm 4^{\circ} \mathrm{C}$. Após quatro semanas, foram avaliadas as porcentagens de explantes responsivos e de contaminação dos explantes, número de gemas e de brotações (>0,5 $\mathrm{mm}$ ) obtidas em cada tratamento.

A análise estatística dos dados foi feita por comparação de médias, pelo teste de Duncan, a 5\% de probabilidade, utilizando o programa SANEST. Os resultados de porcentagem de explantes responsivos e de contaminação foram transformados para $(\mathrm{x} / 100)^{1 / 2} \mathrm{e}$ das variáveis número de gemas e de brotações transformados para $(x+0,5)^{1 / 2}$.

Independentemente da formulação salina utilizada no meio de cultura, os porta-enxertos 'Barrier', 'Capdebosq' e 'Flordaguard' apresentaram maior porcentagem de explantes responsivos e número de brotações, indicando serem mais responsivos in vitro do que as demais cultivares estudadas (Figuras 1 e 2). Para os porta-enxertos 'Aldrighi' e 'GF677', verificou-se efeito significativo da formulação salina usada no estabelecimento in vitro dos explantes, em se tratando das variáveis porcentagem de explantes responsivos, número de brotações e número de gemas (Figuras 1, 2 e 3). Desenvolvimento in vitro diferencial em função da cultivar e do meio de cultura já havia sido verificado em outros porta-enxertos de Prunus (Parfitt \& Almehdi, 1986; Zimmerman, 1988). Por isso, há necessidade da definição da melhor composição para maximizar a propagação in vitro de cada cultivar.

A eficiência de estabelecimento dos explantes, principalmente das cultivares Barrier, Capdeboscq e Flordaguard (>94\%) (Figura 1), pode ser considerada satisfatória ao se comparar com os dados de outros trabalhos descritos na literatura, como os de Rodrigues et al. (2003). No caso dos demais porta-enxertos estudados, onde houve efeito da formulação salina, o melhor meio para o estabelecimento dos explantes foi o QL para a cultivar Aldrighi e o 1/2MS para a 'GF677', respectivamente, com $97 \%$ e $95 \%$ de eficiência de resposta in vitro.

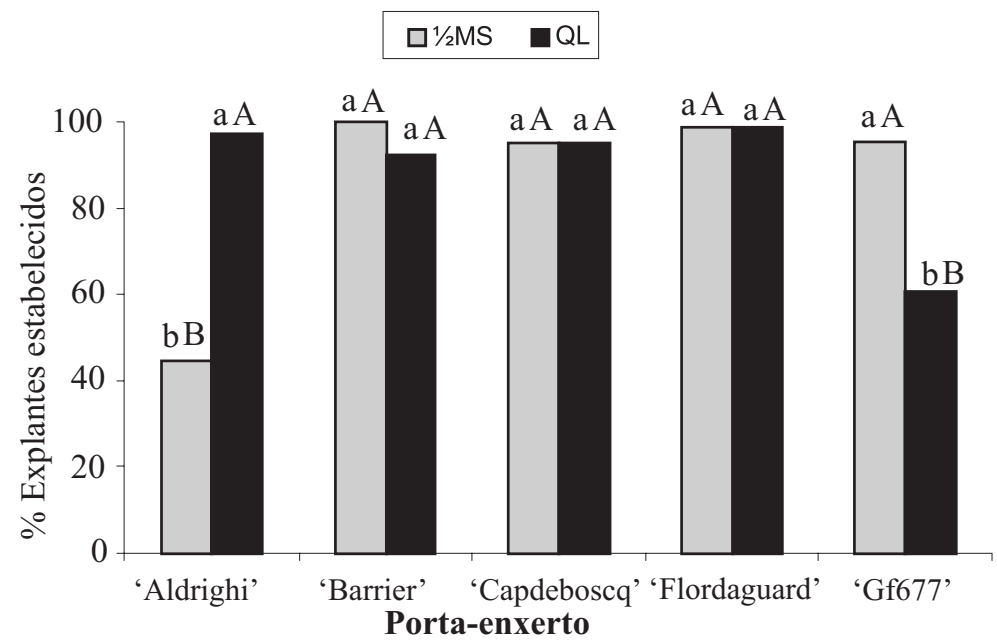

FIGURA 1 - Porcentagem média de explantes estabelecidos de portaenxerto de Prunus sp. nas formulações salinas 1/2MS e QL. FAEM/UFPel - Embrapa Clima Temperado, PelotasRS, 2003. Médias seguidas de mesma letra minúscula, para cultivar, e maiúscula, para meio de cultura, não diferem entre si, pelo teste de Duncan, a 5\% de probabilidade.

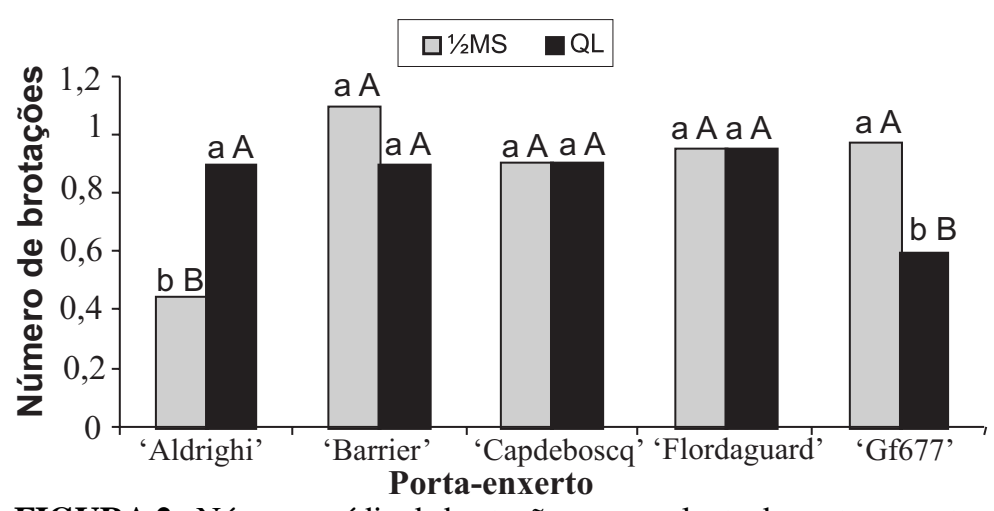

FIGURA 2 - Número médio de brotações por explante de porta-enxertos de Prunus sp. nas formulações salinas $1 / 2 \mathrm{MS}$ e QL. FAEM/ UFPel - Embrapa Clima Temperado, Pelotas-RS, 2003. Médias seguidas de mesma letra minúscula, para cultivar, e maiúscula, para meio de cultura, não diferem entre si, pelo teste de Duncan, a 5\% de probabilidade.

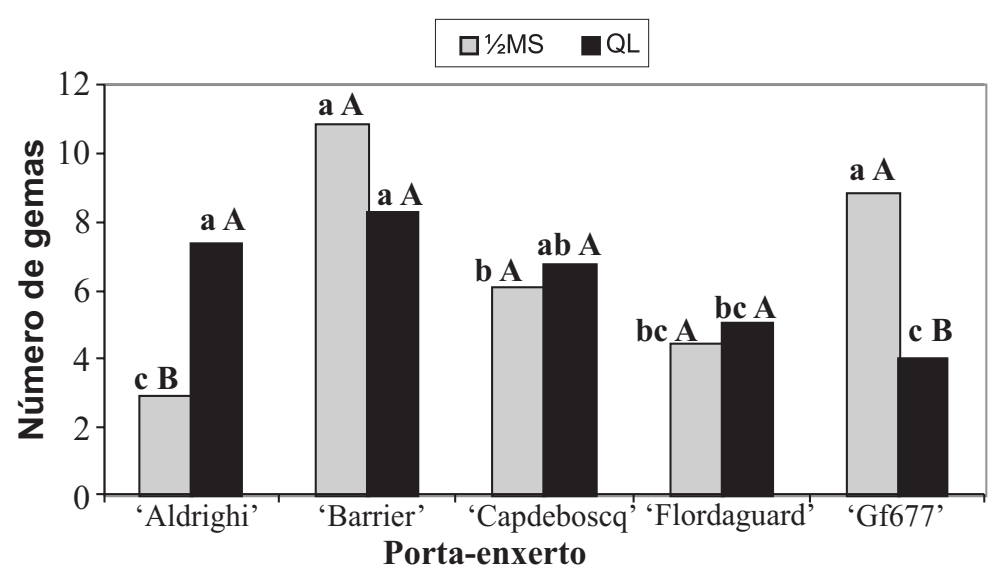

FIGURA 3 - Número médio de gemas produzidas por explante de portaenxertos de Prunus sp. nas formulações salinas 1/2MS e QL. FAEM/UFPel - Embrapa Clima Temperado, PelotasRS, 2003. Médias seguidas de mesma letra minúscula, para meio de cultura, e maiúscula, para cultivar, não diferem entre si, pelo teste de Duncan, a 5\% de probabilidade.

Para a variável número total de gemas por explante, os portaenxertos 'Barrier' e 'GF677' apresentaram médias significativamente superiores às das demais cultivares estudadas no meio de cultura $1 / 2 \mathrm{MS}$. Já no QL, não houve diferença significativa para esta variável, exceto para 'Aldrighi' e 'GF677', onde se obteve resultado superior e inferior ao meio $1 \frac{1}{2} \mathrm{MS}$, respectivamente. Deve-se destacar que, independentemente da formulação salina do meio de cultura, a cultivar Barrier apresentou maior número total de gemas por explante, sugerindo maior potencial de multiplicação (Figura 3).

Durante o experimento, não foram observadas plântulas com sintomas de clorose, vitrificação ou encarquilhamento, indicando que as condições de cultura utilizadas foram satisfatórias. Verificou-se, no entanto, contaminação bacteriana de alguns explantes, por meio da presença de exsudados esbranquiçados no meio de cultura. As maiores porcentagens de contaminação foram verificadas nas cultivares Aldrighi (72\%) e Capdeboscq (41\%), independentemente do meio de cultura utilizado (Figura 4). Curiosamente, há décadas, estas cultivares são as mais utilizadas como porta-enxerto no Sul do Brasil, podendo apresentar maior quantidade de bactérias endofíticas adaptadas às condições edafoclimáticas regionais do que as cultivares introduzidas. Segundo Couto (2003), a contaminação por bactérias tem sido uma das maiores limitações da micropropagação de Prunus, comprometendo o estabelecimento e a multiplicação dos explantes.

De acordo com os resultados obtidos, concluiu-se que as formulações salinas 1/2MS e QL são recomendadas para o estabelecimento in vitro de explantes das cultivares Barrier, Capdeboscq e Flordaguard; 
a formulação salina 1/2MS é recomendada para o estabelecimento da cultivar GF677 e a QL para o da 'Aldrighi'; e a cv. Barrier apresenta grande potencial para multiplicação in vitro.

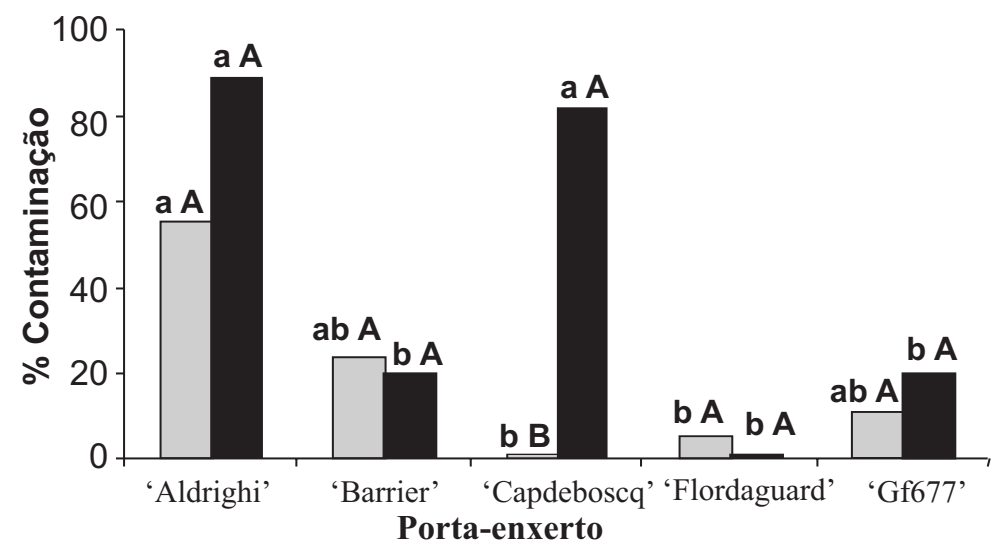

FIGURA 4 - Porcentagem média de contaminação de explantes de portaenxerto de Prunus sp. nas formulações salinas $1 / 2 \mathrm{MS}$ e QL. FAEM/UFPel - Embrapa Clima Temperado, PelotasRS, 2003. Médias seguidas de mesma letra minúscula, para meio de cultura, e maiúscula, para cultivar, não diferem entre si, pelo teste de Duncan, a 5\% de probabilidade.

\section{REFERÊNCIAS}

AGRIANUAL 2003: anuário da agricultura brasileira. São Paulo: FNP Consultoria \& AgroInformativos, 2003. 544p.

BERARDI, G. Coltora in vitro de tessuti e cellule nell'ibrido pesco $\mathrm{x}$ mandorlo 'GF677'; Estudi di induzione morfogenica ed analisi istologiche. Rivista di Frutticoltura e di Ortofloricoltura, Bologna, v.10, p.50-51, 1996.

CHALFUN, N.N.J.; HOFFMANN, A. Propagação do pessegueiro e da ameixeira. Informe Agropecuário, Belo Horizonte, v.18, n.189, p.2329, 1997.

COUTO, M. Propagação in vitro dos porta-enxertos híbridos de pessegueiro 'Barrier' e 'Cadaman' (Prunus sp.) 2003. 77f.
Dissertação (Mestrado em Agronomia) - Faculdade de Agronomia 'Eliseu Maciel', Universidade Federal de Pelotas, Pelotas, 2003

FACHINELLO, J.C. Problemática das mudas de plantas frutíferas de caroço. In: SIMPÓSIO INTERNACIONAL DE FRUTAS DE CAROÇO: PÊSSEGOS, NECTARINAS EAMEIXAS, 1., 2000, Porto Alegre. Anais ..., p.25-40.

FACHINELLO, J.C.; HOFFMANN, A.; NACHTIGAL, J.C.; KERSTEN, E.; FORTES, G.R.L. Propagação de plantas frutíferas de clima temperado. Pelotas: UFPEL, 1994. 179p.

FELIPE, A. J. Portainjertos para duraznero y ciruelo. In: INTA. Curso Internacional de Frutales de Carozo. Rio Negro, 1994. p.1-50.

LORETI, F.; MASSAI, R. Portinnesti fruttiferi; Pesco. L'informatore Agrario, Pisa, v.32, p.37-42, 1995.

MAUCH, C.H. Comportamento de pessegueiros (Prunus persica $\mathbf{L}$. Batsch) e ameixeira (Prunus cerasifera Ehre) em relação à Meloidogyne incognita, 1991. 64f. Dissertação (Mestrado em Produção Vegetal), Escola de Agronomia 'Eliseu Maciel', Universidade Federal de Pelotas, Pelotas, 1991

MURASHIGE, T.; SKOOG, F. A revised medium for rapid growth and bioassays with tobacco tissue cultures. Physiology Plantarum, Copenhagen, v.15, p.473-497, 1962.

OLIVEIRA, R.P.; SILVEIRA, D.G.; SILVA, S.O. Concentração de BAPe a eficiência da micropropagação de bananeira tetraplóide (grupo AAAB). Scientia Agricola, Piracicaba, v.58, n.1, p.73-78, 2001.

PARFITT, D.E.; ALMEHDI, A.A. In vitro propagation of peach; II. A medium for in vitro multiplication of 56 peach cultivars. Fruit Varieties Journal, Urbana, v.40, n.2, p.46-47, 1986.

QUOIRIN, M.; LEPOIVRE, P. Étude de milieux adaptés aux cultures in vitro de Prunus. Acta Horticulturae, The Hague, v.78, p.437-442, 1977.

RODRIGUES, A.C.; SILVEIRA, C.A.P.; FORTES, G.R.L.; FACHINELLO, J.C.; SILVA, J.B. Estabelecimento e multiplicação in vitro de Prunus sp. em diferentes meios de cultivo. Revista Brasileira de Fruticultura, Jaboticabal, v.25, n.1, p.131-133, 2003.

ZIMMERMAN, R.H. Cultivo de tejidos. In: MOORE, J.N.; JANICK, J. (Ed.) Métodos genotécnicos en frutales. Mexico: AGT, 1988. p.167182. 